Georgia State University

ScholarWorks @ Georgia State University

2013

\title{
Taxing the Small: Fostering Tax Compliance Among Small Enterprises in Developing Countries
}

\author{
William F. Fox \\ University of Tennessee, billfox@utk.edu \\ Matthew N. Murray \\ University of Tennessee, mmurray1@utk.edu
}

Follow this and additional works at: https://scholarworks.gsu.edu/icepp

Part of the Economics Commons

\section{Recommended Citation}

Fox, William F. and Murray, Matthew N., "Taxing the Small: Fostering Tax Compliance Among Small Enterprises in Developing Countries" (2013). ICEPP Working Papers. 41.

https://scholarworks.gsu.edu/icepp/41 
INTERNATIONAL CENTER FOR PUBLIC POLICY
International Center for Public Policy Working Paper 13-10

April 2013
Taxing the Small: Fostering Tax Compliance Among Small Enterprises in Developing

\section{Countries}

William F. Fox

Matthew Murray
GeorgaState University
ANDREWYOUNG SCHOOL

OF POLICYSTUDIES 

International Center for Public Policy

Working Paper 13-10

\title{
Taxing the Small: Fostering Tax Compliance Among Small Enterprises in Developing Countries
}

\author{
William F. Fox \\ Matthew Murray
}

April 2013

International Center for Public Policy

Andrew Young School of Policy Studies

Georgia State University

Atlanta, Georgia 30303

United States of America

Phone: (404) 651-1144

Fax: (404) 651-4449

Email: hseraphin@gsu.edu

Internet: http://aysps.gsu.edu/isp/index.html

Copyright 2006, the Andrew Young School of Policy Studies, Georgia State University. No part of the material protected by this copyright notice may be reproduced or utilized in any form or by any means without prior written permission from the copyright owner. 


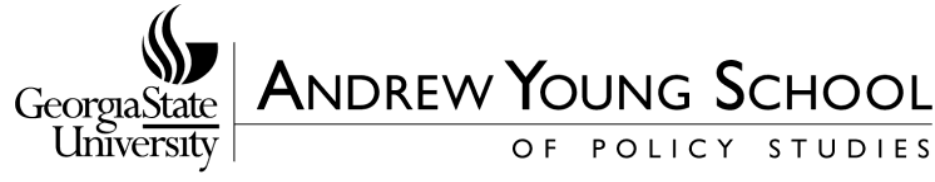

\section{International Center for Public Policy Andrew Young School of Policy Studies}

The Andrew Young School of Policy Studies was established at Georgia State University with the objective of promoting excellence in the design, implementation, and evaluation of public policy. In addition to two academic departments (economics and public administration), the Andrew Young School houses seven leading research centers and policy programs, including the International Center for Public Policy.

The mission of the International Center for Public Policy is to provide academic and professional training, applied research, and technical assistance in support of sound public policy and sustainable economic growth in developing and transitional economies.

The International Center for Public Policy at the Andrew Young School of Policy Studies is recognized worldwide for its efforts in support of economic and public policy reforms through technical assistance and training around the world. This reputation has been built serving a diverse client base, including the World Bank, the U.S. Agency for International Development (USAID), the United Nations Development Programme (UNDP), finance ministries, government organizations, legislative bodies and private sector institutions.

The success of the International Center for Public Policy reflects the breadth and depth of the in-house technical expertise that the International Center for Public Policy can draw upon. The Andrew Young School's faculty are leading experts in economics and public policy and have authored books, published in major academic and technical journals, and have extensive experience in designing and implementing technical assistance and training programs. Andrew Young School faculty have been active in policy reform in over 40 countries around the world. Our technical assistance strategy is not to merely provide technical prescriptions for policy reform, but to engage in a collaborative effort with the host government and donor agency to identify and analyze the issues at hand, arrive at policy solutions and implement reforms.

The International Center for Public Policy specializes in four broad policy areas:

- Fiscal policy, including tax reforms, public expenditure reviews, tax administration reform

- Fiscal decentralization, including fiscal decentralization reforms, design of intergovernmental transfer systems, urban government finance

- Budgeting and fiscal management, including local government budgeting, performancebased budgeting, capital budgeting, multi-year budgeting

- Economic analysis and revenue forecasting, including micro-simulation, time series forecasting,

For more information about our technical assistance activities and training programs, please visit our website at http://aysps.gsu.edu/isp/index.html or contact us by email at hseraphin@gsu.edu. 


\title{
Taxing the Small: Fostering Tax Compliance Among Small Enterprises in Developing Countries
}

\author{
William F. Fox \\ Center for Business and Economic Research and Department of Economics, University of Tennessee. \\ Matthew Murray \\ Baker Center for Public Policy, Center for Business and Economic Research and Department of \\ Economics, University of Tennessee
}




\section{Introduction}

Revenue mobilization in developing countries is challenging and especially so when it comes to generating taxes from small enterprises. This represents a conundrum for policymakers and tax administrators. On the one hand there is a compelling need for revenues to meet spending and social objectives including some semblance of fairness in taxation. At the same time it is widely recognized that in many countries the cost of revenue mobilization from (at least some) small firms-including both administration and compliance costs-exceeds revenue potential. So even if policymakers decide to seek to tax small enterprises, the tax administration may have little enthusiasm for diverting resources from other seemingly more productive uses to enforce taxation of the small.

Defining a "small" business is problematic. In the U.S., the Small Business Administration includes some manufacturing firms with employment up to 1500 in their definition of a small business. The World Bank (2007a), on the other hand, defines micro firms as generally having less than 10 employees, small firms as having 10-49 employees (though there are exceptions) and medium-size firms at 50-249 employees (again with exceptions). In practice small firms can be defined broadly by some of their common characteristics and this is the approach we follow in this paper without a specific attempt to define small. Our discussion applies less to small firms with strong connections to the formal sector and with solid accounting practices. Instead, we focus on small firms that are often ill prepared to comply even with the simplest of tax systems, though there are certainly many exceptions even in very poor countries. Small firms tend to operate on the fringe of the formal economy, with only loose connections to the formal tax and regulatory apparatus of the state. Their activities are often labor intensive, ${ }^{1}$ meaning fewer interactions with market traders of tangible goods who may be in the tax net; they rely disproportionately on cash transactions; there are few opportunities for third-party verification; and they have poor bookkeeping practices. Tax policy is often uniquely designed for small enterprises,

\footnotetext{
${ }^{1}$ The smallest firms frequently rely heavily on the labor of the entrepreneur and her family.
} 
ranging from simple exemptions for small traders under the VAT to the imposition of presumptive tax regimes. Together the characteristics of small firms and their activities offer a weak foundation for voluntary compliance and leave little opportunity for effective enforcement.

There are no good consistent data across developing countries on the magnitude of tax gaps and noncompliance for small enterprises. Schneider et al. (2010) estimate overall GDP gaps on legal activities that range from 34.7 percent in Latin America and the Caribbean to 27.3 percent in the Middle East and South Africa to 37.6 percent in Sub-Saharan Africa. It is difficult to infer the share of these gaps that comes from small firms but it is likely to be significant. Data gathered by the World Bank (2007b) show that micro, small and medium enterprises (MSMEs) share of employment is 49.4 percent in lowincome countries and 53.9 percent in low, lower-middle and upper-middle income countries. In the end, tax gaps from small enterprises must be made up by higher taxes on compliant agents or foregone public services.

The relationship between revenue authorities and potential taxpayers has traditionally been viewed narrowly as a game theoretic principal-agent problem, which certainly has merit. This fits nicely with the often adversarial relationship between taxpayers and revenue authorities where each party operates with some degree of uncertainty and antagonism regarding the behavior of others. It is also consistent with negotiated tax settlements that are common in developing countries.

However, it has become apparent that there is more to the compliance game than simply administrative enforcement of taxes imposed on the unwilling. Interactions between taxpayers and the state represent an important facet of the evolving and arguably endogenous social contract in developing countries and this is not easily accommodated by classical models of underreporting and compliance. This is especially important for small firms since the first direct, formal contact with an arm 
of the state may be interaction with tax authorities. ${ }^{2}$ If this interaction goes poorly it may weaken the social contract and support for the state, along with the will to comply. It is entirely possible that negative relationships - created by unsympathetic, arbitrary or especially egregious administrative behavior-create the will to cheat as a form of spite or reciprocity. ${ }^{3}$ If policymakers decide to tax small enterprises, the absence of a strong and credible will to tax, along with administrative inefficiencies and corruption, can compromise the tax enforcement climate, diminish revenue productivity further and harm the perceived fiscal exchange between taxpayers and the state. It may be better to not tax at all than to tax poorly.

Developing countries must first decide whether or not to tax small enterprises. If the decision is made to tax, the actual tax instrument must be designed and implemented, along with the enforcement regime and administrative policies and procedures that will define the relationship between taxpayer and state. Traditional arguments for taxation of the small include revenue need, the pursuit of taxpayer neutrality across businesses of different size and enhancement of the overall enforcement regime via inclusion of more firms in the tax net (to facilitate cross verification). Also, the failure to tax small enterprise creates incentives for firms to remain small or to use the "small" loophole to avoid or evade taxes; in such instances one would expect to see relatively large numbers of small firms bunching up at the kink point where the system of taxation for larger enterprises is implemented. Secondary arguments justifying taxation of the small have more recently been articulated. One such argument is that "formality," i.e. firm engagement with the formal sector as opposed to informal sector of the economy, will improve economic growth. So if firms can be nudged into compliance with the tax system, they may then comply more broadly with the state's regulatory apparatus, access market

\footnotetext{
${ }^{2}$ We are not suggesting that all small firms are new. The most successful small firms become large and the least successful go out of business leaving a set of new and stable small firms.

3 Jolls et al. (1998) note (pp. 1546) that "Some predictions of the standard model are simply wrong. For example, people can be both more spiteful and more cooperative than the traditional analysis predicts..."
} 
resources like credit, interact more fully with other enterprises and grow at a stronger rate. There is also the growing perception that fair and effective taxation of the small provides spillover benefits. For example, if taxation of the small enhances society's perception of the compliance regime and fairness of the tax system, others will more willing comply without increased usage of costly enforcement sticks.

This broader perspective of compliance and enforcement is not easily accommodated by neoclassical models of criminal behavior which have been applied to understanding the compliance game and designing enforcement mechanisms. Behavioral economics, which introduces broader social and psychological influences, may be a better construct to understand how relationships between taxpayers and the state affect compliance. These seemingly modern ideas have early antecedents in the developing country context. For example, the introduction of the Blue Return system in Japan in 1950, which included positive inducements for compliance and is discussed more fully below, was advocated by Professor Carl Shoup as part of the post-war Shoup Mission. Much later, Shoup (1976) attributed the modest use of urban real estate taxation in developing countries to sociology, political science and anthropological factors. Bahl and Schroder (1983) note that there may be "...a psychological incentive to pay if a taxpayer is among neighbors who are complying with the law." ${ }^{4}$

In what follows we first discuss a more nuanced view of the tax compliance game from the evolving perspective of behavioral economics. This discussion is followed by a more traditional analysis of issues related to taxation of the small drawing on recent insights and policy interventions. Our discussion generally blends issues of tax structure with various facets of tax administration and enforcement. In most instances the tax instrument in question is the VAT since it is the dominant revenue source in most

\footnotetext{
4 Jolls et al. (1998) provide a general discussion of neoclassical and behavioral models of law and economics. Alm (2010) applies behavioral economics to the field of public economics, including tax compliance. Also see the collection of essays in Alm, Martinez-Vazquez and Torgler (2010).
} 
developing countries, though we recognize there are compliance problems with all revenue instruments.

A primary conclusion of our work is support for integration of small firms into simplified tax systems that will lead taxpayers into the general and regular system of taxation for larger businesses as they grow and prosper. This might include a VAT with thresholds to exempt the smallest of traders and simplified reporting procedures that can nurture compliance. We generally offer little support for alternative tax systems, in particular presumptive regimes, which can complicated, onerous, entail administration of multiple tax systems and do a poor job of preparing taxpayers for the regular system of taxation. Administration and enforcement should include comprehensive registries of firms, some form of regular filing or contact requirements with the revenue administration and rewards for good compliance behavior. We recognize that there may be circumstances where it is better to not tax the small. These situations are most likely to arise when tax capacity is exceedingly low and there is little confidence in the capacity of the state to administer the rule of law. We also argue for a broader perspective on the role of the tax administration apparatus in developing countries. The importance of nation building and a sound social contract point to the need to create a healthy rather than adversarial relationship between taxpayers and the revenue authorities. This is problematic in practice since it represents a sharp departure from current policy and will entail new models of training for administrative personnel.

\section{Behavioral Economics: New Perspectives on the Compliance Game}

Research on compliance has traditionally focused on maximizing the collection of revenues that are due given resources available to the tax administration. Efficiency requires consideration of excess burdens, as well as the costs of administration and compliance, but tax administrators are prone to focus on revenues at the expense of other considerations. More recently research has broadened the 
goals to include the important roles that taxation can play in bringing businesses into the formal sector and encouraging state-building. This broader behavioral perspective is especially important for small firms because of agent's direct interactions with the revenue authorities. Owners of large firms, on the other hand, often rely on legal and accounting staff, along with other professionals who are tasked with the tax reporting process.

\section{The Allingham-Sandmo Model}

Allingham and Sandmo (1972) provide the classical framework for explaining individual taxpayer compliance behavior and rationalize and guide administrative enforcement efforts. In principle the model is especially well suited to small enterprises by virtue of the individual agent-as opposed to a formal business establishment-making choices regarding the degree of compliance with the tax system. ${ }^{5}$ This framework has its roots in early stick models of criminal behavior with agents narrowly deriving utility from own income net of taxes and expected penalties on underreported income; expectations are assumed to satisfy the assumptions of expected utility theory. By focusing on the taxpayer's choice of underreported income and emphasizing the role of penalties, there is a natural linkage to enforcement through traditional examinations, audits and administrative/criminal penalties for noncompliance. (The literature is largely silent on how behavioral responses to audit probabilities and penalties are shaped.) The Allingham and Sandmo perspective is likely the mental construct used by most analysts and policymakers today in framing the tax compliance game. For example, Sarker (2003) discusses compliance problems associated with the self-assessment system in Bangladesh and points to weak penalties as one of the main impediments to improved administration and revenue collection. But there are important exceptions where a broader view is applied. For example, the Tanzania Revenue Authority has shifted its emphasis away from enforcement and more toward compliance carrots

\footnotetext{
${ }^{5}$ Everest-Phillips (2008) indicates that analysis of business taxes has focused on compliance costs and efficiency with little consideration of the underlying motivations and the broader willingness of firms to pay.
} 
(Foreign Investment Advisory Service, 2006). While this is a potentially important step, there is virtually no knowledge of the returns to the application of kindness and carrots to tax compliance.

Despite the popularity of the Allingham and Sandmo model, there are several reasons to reject it as a complete characterization of compliance behavior. First, the magnitude of expected penalties is in practice generally too low to explain observed rates of compliance across both developed and developing countries. McCaffrey and Slemrod (2006) argue that this criticism of Allingham and Sandmo is overstated since a large share of income is matched by third party reporting and thus not even subject to traditional enforcement efforts. However, even accounting for this pattern of matched income, McCaffrey and Slemrod acquiesce and conclude that other factors must nonetheless be at play in explaining rather pervasive patterns of compliance in the face of low audit odds. There is related evidence from the laboratory that subjects overstate audit probabilities (Alm, McClelland and Schulze, 1992). But there is no neoclassical explanation of why this might be the case.

Second and related, there is empirical and experimental evidence to suggest that various notions of fairness regarding the behavior of others (e.g. reciprocity), fiscal exchange and the quality of governance affect compliance patterns (e.g. Cummings et al. 2009). Similarly, there is evidence from a wide class of public goods experiments that there is more cooperation and less free riding than would be predicted by theory. Together this evidence suggests that own compliance behavior can be affected by the compliance behavior of other individual agents, the nature of taxpayer relationships with revenue authorities and the quality of the quid pro quo between tax payments and government services. These conclusions go well beyond the boundaries of the Allingham and Sandmo model. Classical incentives matter, but so do other considerations. These other considerations may go a long way toward explaining why the returns to classical enforcement efforts vary across countries and regions. This may 
be especially important to small firms who likely hold first-hand knowledge of the compliance behavior of other small firms and have direct contacts with revenue authorities.

Finally, extensive laboratory experiments have rejected the expected utility approach to explaining behavior under uncertainty. ${ }^{6}$ Prospect theory and loss aversion, concepts formalized by Kahneman and Tversky (1979), have been shown to have considerably broader explanatory power than expected utility theory. As discussed below, this alternative view of uncertainty has potentially important implications for the penalty-reward structure of the enforcement regime targeted to small entrepreneurial enterprises.

\section{Behavioral Public Finance}

Behavioral public finance offers a potentially promising complement to the classic Allingham and Sandmo model, whether applied to a developing or developed country context. ${ }^{7}$ For example, the role of penalties offers some important lessons. Frey (1997) distinguishes between intrinsic motivations to comply based on civic obligations versus extrinsic motivations that emanate from the threat of the enforcement regime. Everest-Phillips (2008) links the intrinsic motivations to state-building and argues that political inclusion, accountability and transparency, perceived fairness, effectiveness, and political commitment to share prosperity are the key elements to building intrinsic motivations. He goes on to contend that bringing small businesses into the tax net is an important component of bringing them into the formal sector. Encouraging firms to join the formal sector is important because these firms grow much more rapidly and they may help other businesses grow as well, so small business tax policy can be a key element to motivating much needed economic growth. Frey shows that more vigorous enforcement efforts can crowd out the intrinsic motivations that are essential to state building. The

\footnotetext{
${ }^{6}$ For a review, see Camerer et al. (2004).

${ }^{7}$ In addition to the general review of behavioral economics by Camerer at al. (2004), see McCaffrey and Slemrod (2006) for a more focused discussion of behavioral public finance.
} 
consequence is that people pay a higher share of their taxes not out of any civic obligation or duty to the state but because of the fear of retribution and penalties. This can potentially weaken the nature of the fiscal exchange between taxpayer and state and have broader social implications.

However, broadening the tax base to small firms may generate little if any new revenues (particularly when one accounts for administration and compliance costs), whether motivated intrinsically or extrinsically, and may not be justifiable based on net revenue maximization. The decision on whether to tax small businesses should be judged in terms of the broader set of objectives. For example, by reducing the size of the informal sector one expands the legitimacy and perceived fairness of taxes to others in the tax net and builds linkages to foster growth of the state.

Prospect theory and penalty (loss) aversion indicate that similar gains and losses from some reference point do not have the same magnitude of positive and negative effects on utility. An immediate implication is that rewards as opposed to only penalties surface as an important means of affecting compliance behavior. Falkinger and Walther (1991) introduce positive inducements into the Allingham-Sandmo model and show that a mixed strategy that includes rewards and sanctions is often superior to a pure penalty-based system. Ventry (2008) similarly argues that tax enforcement currently "...relies too heavily on sticks and not enough on carrots." He views rewards for compliant taxpayers as a complement to penalties on the noncompliant, not simply a substitute. More generally Ventry makes the case for a more cooperative and constructive relationship between revenue authorities and taxpayers. There is nothing in traditional models of criminal behavior and tax enforcement that would directly support such a cooperative approach to compliance and administration.

Incentivizing compliance through a reward structure will strike some as a peculiar means of getting taxpayers to do what they are obligated to do, similar to a bonus that is provided to a worker who shows up to work on time. But there is evidence that these rewards can enhance behavioral responses. 
Early evidence comes from the Blue Return-White Return system that was introduced in post-war Japan in 1950 at the recommendation of the Shoup Commission (Tanabe, 1973). Japan faced a dramatic need for revenue mobilization but dealt with taxpayers who had little in the way of formal books and records to support self assessment of tax. A culture of compliance and honest self assessment was lacking at the time which further compromised compliance. Taxpayers with proper books and records were allowed to submit Blue Returns that were accompanied by reduced sanctions and special provisions like loss carryforwards and carrybacks, and allowed deductions for family employees in order to facilitate separation of household from business finances. Taxpayers submitting White Returns were denied these same benefits. Importantly, audits of Blue Returns were confined to information maintained in regular books and records; audits of White Returns were subject to averages and standards akin to modern presumptive regimes. An important objective of auditing was to improve recordkeeping practices. With time there was substantial improvement in compliance and significant growth in the share of Blue Returns.

There are also more recent examples of positive incentives for compliance. For example, Tanzania and Pakistan have each implemented a carrot compliance model under the VAT whereby traders in good standing are given accelerated refunds (Foreign Investment Advisory Service, 2006). In Tanzania all VAT refunds are in principle to be provided within 30 days, while Gold and Silver status taxpayersthose with good compliance histories-receive expedited refunds. The classic penalty structure has not been abandoned. Those traders with compliance irregularities or with neither Gold nor Silver status are subject to audit prior to the granting of refunds. Like the Blue Return system in Japan, this approach encourages proper recordkeeping to support self assessment and administrative enforcement.

Of course what matters most is what the tax administration does in practice and this can have an important bearing on taxpayer attitudes. The Foreign Investment Advisory Service notes that best- 
practice requirements for achieving Gold or Silver status are not transparent, which can create uncertainties and distrust, and thus potentially offset any gains that might otherwise arise from the use of carrots. Manufacturing firms have noted that they are still required to provide verification for every VAT refund claim which renders the carrot (i.e. risk assessment) system largely ineffective and irrelevant.

A second and less obvious implication of prospect theory is that a series of small gains are preferred to a singular, aggregated gain, while an aggregated loss is preferred to a series of smaller, disaggregated losses (Krishna and Slemrod, 2003). Thus any incentives and rewards for compliance should be small (and salient) but spread out over time. The expedited VAT refunds noted above are consistent with this principle. Penalties and tax remittances, on the other hand, should be subject to aggregation rather than spread out across time. Unfortunately there is no direct empirical evidence to support such conjectures.

Salience has surfaced prominently in the new behavioral economics literature and requires transparency and meaningfulness in order for behavior to be affected by policies and other parameters. The enforcement/reward structure of the compliance regime, along with administrative procedures and provisions, must be clearly understood by taxpayers and have reasonably certain and significant consequences in order to be effective. This is not likely to be the case for many small enterprises that have tenuous and limited interactions with revenue authorities and other elements of the state's regulatory system. Many tax regimes allow rebuttable assessments that may diminish salience in the eyes of the taxpayer. More generally, corruption, bribes, and gross inefficiencies in tax administration in developing countries may cause the enforcement apparatus to be indirectly compromised.

Salience also suggests that voluntary remittance of tax must map visibly and significantly into public service provision and the safety and security offered by the state. Small, irregular tax remittances and 
presumptive or two-tiered tax systems may signal to taxpayers that their tax contributions are of inconsequential value to the state; taxpayers may also feel that they are of secondary value relative to other taxpayers. This argues for including small business enterprises into the regular system of taxation applied to larger firms. Of course, the benefits of feeling connected to an overall tax structure imposed on all business must be balanced against the administration and compliance costs associated with enforcing taxes on large numbers of small businesses. Indeed, a complicated general business tax structure may not be salient to many small firms, even if it is the same structure levied on larger firms.

The way in which tax payments are framed in the eyes of small enterprises may be portrayed as form of price presentation per the marketing research literature (Krishna and Slemrod, 2003) and can affect the salience of taxation. For example, there is evidence that separately stating sales taxes and product prices leads to the perception of lower product prices (Chetty et al. 2009). Kamleitner et al. (2012) find that small businesses frame their tax payments as painful losses. It is possible that an indirect tax like the VAT, which one could argue is collected on behalf of consumers rather than taken from the income of the business enterprise, may lead to less mental distress than an income or presumptive tax that is perceived to be taken from the resources of the entrepreneur. Prospect theory and framing together may be arguments against presumptive tax regimes. As Krishna and Slemrod note, reductions in tax burden from some base are viewed as gains. Thus a tax that allowed for adjustments to the base to arrive at the tax burden - whether an income tax or VAT-may be preferred to a system that is framed as a lump sum burden that can only be reduced through an onerous rebuttal mechanism with the tax administration.

At a more general level are other-regarding preferences that may capture social norms and responsibilities, inequities in fiscal exchange and the political process, reciprocity and fairness. Unlike traditional neoclassical preference structures where utility depends on own characteristics like own 
leisure and own consumption, other-regarding preferences allow behaviors and outcomes of other agents to affect own utility and own behavior. One class of other-regarding preferences characterizes some goods as being positional or having status associated with their consumption, as with extravagant vacation homes (e.g. Ireland, 2001). A simple representation would be own consumption relative to mean consumption of society at large or some peer group such as co-workers or one's neighbors; an increase in own consumption relative to the mean would increase utility, while an increase in mean consumption with no increase in own consumption would diminish utility. The important implication of other-regarding preferences in the compliance context is that the behavior of others-taxpayers, tax administrators, the government at large and so on-can affect own wellbeing with no change in own behavior. At the same time, the behavior of others can induce changes in own behavior even absent changes in traditional parameters like own income, prices, tax rates and penalties.

The likely presence of other-regarding preferences poses both challenges and opportunities. The challenge arises from the greater complexity of the preference structure; opportunity arises through the possibility of a social multiplier whereby inducing positive changes in one's behavior can lead to positive changes in the behavior of others. Consider, for example, the notion of positional compliance where one's degree of tax compliance depends on mean compliance of society. Classical enforcement activities that diminish the noncompliance of others may also serve to diminish own noncompliance. ${ }^{8}$ Coolidge and Ilic (2009) survey informal firms in South Africa and find that those that are likely to move to the formal sector and register for tax perceive that other enterprises pay their taxes. Other policies that enhance compliance may have similar effects.

There is considerable evidence that various notions of fairness and the broad nature of the relationship between taxpayer and state have an important bearing on compliance behavior. Kirchler

\footnotetext{
${ }^{8}$ In practice it may be impossible to distinguish between enhanced compliance arising from other-regarding preferences and improved compliance from an enhanced enforcement regime.
} 
et al. (2010) emphasize the importance of a service-oriented attitude to tax enforcement that may help convey the fairness of the tax system and fiscal exchange with the state. Schnellenbach (2010) focuses on vertical reciprocity (taxpayer-state) and horizontal reciprocity (taxpayer-taxpayer) in affecting compliance. Alm, McClelland and Schultze (1999), use laboratory experiments to show that when higher enforcement parameters are rejected by voters, noncompliance grows pointing to the broad importance of social norms. Bird et al. (2007) find that tax effort in developing countries depends on the degree of corruption, public sector accountability and the efficacy of public institutions in supporting voice and participation. Richardson (2006) conducts a cross-country empirical analysis that points to the importance of fairness and tax morale in affecting aggregate compliance behavior. ${ }^{9}$

Nothing here is meant to suggest that the Allingham and Sandmo framework should be discarded. But there is a much broader social and political context within which self-interest is exercised and classic enforcement activities take place that must be recognized. Traditional enforcement, from simple interest charges to criminal sanctions, will remain important because we know that people are motivated by basic incentives and disincentives. But consideration should be given to mechanisms whereby rewards can be structured to induce and enhance compliance. This is easier said than done, especially in light of the paucity of guiding empirical evidence. More generally there should be increased recognition of and emphasis on social and political interactions that frame attitudes toward fairness and the quid pro quo between taxpayer and state. In this context attitudes are endogenous and will depend on the actions of agents of the state. Unfortunately, we know terribly little about how to change these attitudes and the costs that would be incurred in doing so. This is especially problematic if the only available resources are currently employed in the application of traditional enforcement activities.

\footnotetext{
${ }^{9}$ Torgler (2002) provides a survey of the literature on the influence of tax morale and social norms on tax compliance. Also see Alm (2010) for a review of tax compliance experiments that point to the importance of social norms in affecting behavior.
} 


\section{To Pay or Not To Pay}

Small enterprises must decide whether they want to opt (or stay) out of the tax system, participate partially with the tax system (e.g. register with tax authorities but underreport income/taxes or file irregularly) or fully opt into the tax system and thus the formal sector. As such the compliance decision of the firm can be viewed as a continuum ranging from no compliance (informality) to complete compliance (formality). The scope of participation will depend on a host of considerations that reflect the activities and objectives of the business enterprise and the nature of the state's tax and regulatory apparatus.

Two broad categories of possible incentives and disincentives to participate in the tax system are market considerations and public policies. Businesses that engage solely in illegal activity will generally choose not to participate, while those partially involved in illegal sector activities as well as above ground activities may have considerable incentive to comply (at least partially) in order to mask and launder some business activities. Such firms may generally choose to operate in the middle of the compliance continuum, paying all or much of what is due on legal activity and masking illegal sector activity through creative bookkeeping. It is entirely possible that the costs of being in the middle exceed the costs of complete informality or formality, but the returns to evasion may more than offset these costs.

Enterprises engaged in legitimate market activities face numerous incentives to formally participate in the tax system and register and file returns and reports, but there will generally be some temptation to underreport taxes. These incentives need to be highlighted in the eyes of fledgling taxpayers. Many businesses, especially businesses that have plans for growth, need access to formal capital markets and participation with the tax system may be a necessary antecedent to accessing financial capital. Access to public sector contracts will also hinge on participation with the tax system. (The incentive to contract 
with the state could easily be dampened or negated by corruption and rent seeking in the allocation of government service and acquisition contracts.) There may be other market incentives as well, for example the desire to use marketing techniques and advertising services that would otherwise possibly expose the firm and its activities to the revenue authorities. ${ }^{10}$ Finally, depending on the product or service, consumers would likely prefer purchasing from legitimate enterprises in order to have the opportunity to return or exchange products and receive warranty service. This would be less important for the labor intensive services that many informal firms provide to their customers, such as personal transport. Licensure may also be an important consideration to the extent that licensed sellers provide greater quality assurances.

Public policies may offer both incentives and disincentives to participate in the formal sector as a legitimate enterprise. For example, firms may want recourse to police and court services to protect their private property which provides an inducement to participation and some degree of compliance. A corrupt enforcement and legal system may fully compromise this incentive. Participation in the tax system will also expose a firm to the full regulatory and licensure apparatus of the state which could be costly. Corruption, ineptitude and administrative inefficiencies will increase these costs further. As with market-based incentives, taxpayers should be made aware of the public sector benefits that accrue from full participation in the formal sector.

The fiscal system imparts both direct and indirect influences on the choice to comply with the tax system. Presumptive tax regimes are used when observability is compromised or sharply constrained, as with small firms that rely on cash transactions. They are also intended to offer some relief from the compliance and tax burdens that would otherwise arise if firms were placed in the "regular" tax system. For example, Tanzania employs a presumptive tax system based on turnover where firms can pay a flat

\footnotetext{
${ }^{10}$ See International Finance Corporation (2007) for further discussion of advantages and disadvantages to compliance.
} 
fee if they keep no formal accounts or a two-part tax (flat rate plus percentage) for those firms that keep records.

But regardless of how these presumptive systems are structured, they do entail some compliance cost and necessitate some payment of tax relative to completely opting out of the system. In many instances the tax burden may have little or no bearing on the taxes that might accrue from accurate self assessment and reporting. In practice, the tax burdens of the presumptive regime can be relatively high and create a significant disincentive to market participation. For example, Stern et al. (2005) calculate marginal effective tax rates (METRs) for the presumptive and general tax regimes in South Africa, Zambia and Rwanda. In each case they find that the presumptive regime leads to substantially higher marginal tax rates.

While these presumptive tax regimes can represent an impediment to formality, they offer some encouragement for firms to grow and move to the general system of taxation. But there is an important question as to whether they nurture desired behavior, in particular the cultivation of formal records and books that can support tax compliance and also facilitate business management. It appears that presumptive taxation is used as a stopgap measure to generate revenue and provide some degree of a level playing field relative to larger and better-established enterprises. If these systems are used, they should be structured to achieve longer-term policy objectives including accurate recordkeeping.

Small traders' participation in the VAT regime in most countries may be precluded by sales thresholds. The International Finance Corporation (2007) reports that small enterprises in South Africa confront very high marginal effective tax rates (METRs) on their capital expenditures because of their inability to receive relief on input purchases. Of course the same enterprises are not required to charge VAT on their sales so the net tax impact will depend on the profile of the firm in question. Compliance costs are relatively high for smaller businesses because of fixed costs of compliance (including the need 
to keep formal books and accounting statements) and the small volume of trade. Compliance costs and the competitive advantage from not charging VAT on sales may together be substantial and provide significant encouragement to noncompliance.

For fully-qualified traders the VAT offers relief on input purchases, but compliance with the VAT also reduces opportunities for additional sales and market penetration via undercutting the tax-inclusive price charged by other traders. This would be especially true of retailers making sales to final consumers. Traders in the middle of the supply chain would likely have fewer opportunities to engage in this behavior since other firms would want access to the full value of credits on purchases.

\section{Fostering Compliance through Tax Administration}

Research over the past four decades evidences the importance of tax administrators viewing and structuring their role and approaches based on a broader perspective of the incentives and goals for paying taxes than is seen in the Allingham and Sandmo model. Tax administrators must also be evaluated using a much broader set of goals than simply a revenue generator if taxes are expected to be a major tool for linking taxpayers to the state. The goals, which include collecting revenues, limiting administration and compliance costs, and building linkages to the state, must be recognized when incentives are created for taxpayers and when tax administrations are evaluated. ${ }^{11}$ This will require creation of a new culture within governing bodies and the tax administration and will require new models of training for administrative personnel, especially those with direct interactions with taxpayers.

\section{Expanding Expectations for Tax Administrations}

\footnotetext{
${ }^{11}$ It is common for the tax code to be used to pursue additional social policy objectives, especially in developed countries. Taxpayers may incorrectly attribute the pursuit of these objectives to the tax administration while in reality their source lies with the legislative and/or executive branches of government. The role of the tax administration in these contexts can also be expected to shape taxpayer linkages to the state.
} 
The more complicated incentives and goals significantly raise the challenges for tax administrators but also the mechanism for evaluating their performance. Establishing tax administrations that meet such extensive expectations is especially difficult in countries where taxes are collected at both the national and sub-national levels, which is common for at least some taxes. Thus, many, not just one tax administration must envision their responsibilities more broadly and must become service oriented and client friendly. The importance of also building effective local administrations is magnified because local taxes likely impose the greater compliance burden (at least relative to revenues collected) because many small tax instruments are often levied (World Bank, 2007). While the burden of each instrument may be modest, the collective burden across a number of small taxes can be substantial.

Responsibility for achieving broad goals for taxation must be seen even more inclusively than just the tax administrations if government accountability, transparency and fairness are driving forces behind achieving the goals of taxation. Essentially all ministries, and certainly those involved in regulation, have a role in building an environment that encourages taxpayer compliance. Simply put, good government and constituent responsiveness are factors in determining willingness to pay and to be part of the formal sector. The tax administration cannot be expected to fully offset perverse effects of onerous regulatory environments and bad government. Thus, performance of the tax administration should be evaluated in the context of the overall context where it operates.

Still, a highly professional tax administration is a key aspect to motivating compliance. A combination of properly designed carrots and sticks is appropriate, but many other tools must be in the administration's toolbox. Some of these tools can be exercised at the discretion of the tax administration and others are dependent on enabling legislation. Strong enforcement of the tax regime across a wide array of taxpayers, or at least the perception of enforcement, is essential to accounting for other-regarding preferences and to enhancing voluntary and non-confrontational willingness to pay tax. 
Salience is essential, which means an understandable tax code, good taxpayer information and low corruption, and ideally some clear connection between the payment of taxes and the services received from government. The bottom line is that a skilled, professional tax administration is integral to small firms becoming part of the formal economy and paying taxes. Sticks will ensure some compliance, but likely far short of a broader conception of how to bring small business into the formal sector including the tax regime.

\section{$\underline{\text { Importance of Low Compliance Costs }}$}

Both the compliance and tax burden costs must be kept low if small firms are to be expected to join the formal sector. Many countries, perhaps inadvertently, fail particularly when it comes to maintaining low compliance costs. The number and complexity of taxes at both the national and sub-national levels are important determinants of small business compliance costs and the broader costs of joining the formal sector. For example, Everest-Phillips (2008) reports that local governments impose 1500 different taxes in Yemen, which makes the burden of knowing which apply a significant cost before complying with the ones that are imposed on a particular firm. It is important to remember that the entire set of taxes and not just the taxes that are specifically intended as levies on business (i.e. the VAT) can burden small firms. ${ }^{12}$ Businesses perform much of the compliance for individual taxpayers in many cases, such as with the sales and excise taxes and the VAT. All of these entail significant compliance costs that are seldom reimbursed by government. ${ }^{13}$

Compliance costs encompass monetary, time, and psychological elements and all of these must be considered by the tax administration (World Bank, 2007) because they reflect the social cost of the tax

\footnotetext{
${ }^{12}$ Annual studies by Ernst and Young (2012) for the Council on State Taxation have estimated that over 90 percent of state and local taxes paid by business in the U.S. come from taxes other than the primary specific tax on business, the state corporate income tax. Most are taxes intended to be levied broadly on people and business, such as the property and sales taxes and excises on oil and gasoline.

${ }^{13}$ A number of U.S. states compensate vendors for some compliance costs associated with the sales tax.
} 
system. The time taken to file returns, react to frequent legislated changes in tax structure and provide information for multiple audits are factors that rank high in surveys on factors that create compliance costs. The evidence suggests that these costs are relatively greater for small firms than for larger ones, and particularly in the case of the VAT. The fixed costs associated with complying with multiple tax instruments can be expected to be especially onerous for the small.

A multitude of different taxes, each generating small amounts of revenue and imposing unique compliance burdens, may cause taxpayers to question the efficacy of the state. In practice each of these taxes may represent an important source of revenue mobilization in developing countries. But firms paying these same taxes may not see the connection between tax payment and the provision of services. It may be better to consolidate tax instruments and use other means (such as earmarking or formula allocation) to fund programs that might otherwise be funded by a series of small levies. This approach may also produce resource savings in tax administration.

\section{Principal/Agent Concerns}

Enforcement of the tax regime must also recognize that tax administrations' are not merely faceless organizations staffed by people who collect government revenues but institutions with their own incentives and agendas. Principal/agent problems can arise in tax administrations just as in most other institutions. In part, tax administrations will respond to the incentives placed before them and they have traditionally been evaluated and rewarded based on the revenues they collect, including arrears and penalties. A simple evaluation of effectiveness based on revenue generation lessens the motivations for drawing small firms, many of which will generate little if any tax revenue in the short term, into the formal tax system. Tax administrations also will be inclined to ignore compliance costs if tax revenues are all that matter. Thus, tax administrations must be confronted with a broader set of incentives if they are to play an important role in creating intrinsic motivations and undertaking nation building as well as 
the everyday responsibilities of operating the tax system. Similarly, incentives facing individual tax collectors must be brought in line with the broader expectations for the organization. Issues such as corruption and graft in imposition of taxes on small business must be addressed and countered.

The principal/agent problem can be aggravated in at least two ways. The first is when regional or local governments serve as the collection arm of the national government. This form of government tax farming - which is a complicated extension of vertical reciprocity - can naturally create tensions between the local tax collector and local firms, as well as the central government body overseeing the tax. A second problem can arise when local tax collectors charged with collecting local or regional taxes are spatially distant from supervisory agents in the local tax administration. There may be inherent tensions in such contexts that are difficult to overcome in practice. Similar principal/agent problems can arise when national officials are located far from the capitol and regional managers.

Failure to broaden the tax base to small business likely means higher tax burdens on larger formal sector firms if revenue goals are to be met. Economic growth will be hampered by the higher effective rates on large firms but also the higher rates will discourage firms from expanding and joining the formal sector. Strong economic growth almost surely relies on rapid increases in the number and size of small enterprises so it is important to encourage their development and expansion - this is not to suggest that small firms should be free of tax. Research has tended to find that the formal sector is more productive and grows faster than the informal sector (Palmade, 2005), evidencing the importance of drawing small firms into the formal economy. Small firms often understand the benefits of being in the formal versus the informal sector, including avoiding corruption and payments to remain informal, which goes to the heart of the tax administration (Everest-Phillips, 2008). The tax administration can go far by facilitating entry to the formal sector as it provides information on how to comply with regulations, taxes, and other aspects of the formal sector. This broader facilitation role must be recognized by the tax 
administration and supported by education and training programs that can nurture firms into compliance.

\section{Implications}

We return here to the question posed in the introduction: Should developing countries seek to tax small enterprises? Our first response is to waffle and say "it depends." In fact it does depend. For example, if revenue administration is of sufficiently poor quality, then there is no reason to divert resources to administration of tax on a new, much larger set of taxpayers. The discussion of taxpayers' motivations presented above evidences that behavior by the tax authorities and legislated tax structure each have important implications for the incentives and motivations that prompt taxpayer compliance. Poor administration of tax could conceivably do more damage than good since it lessens the potential to collect from more lucrative taxpayers without providing a positive relationship with government and incentives to formalize the business entity. If the decision to tax the small is made, this decision must be predicated on a careful cost-benefit calculus that yields well-defined goals, objectives and ultimately policies associated with administration and the evaluation of administrative personnel. A wellarticulated plan for meeting these goals must be in place for meeting the goals.

Our discussion above suggests that small firms should be part of the same common tax structure applied to larger firms, though some adjustments could be possible such as semi-annual rather than monthly tax returns if dictated by cost considerations. A small or no threshold for VAT taxpayers is also indicated, though this varies from the recommended practice by the IMF which is a relatively high threshold.$^{14}$ Further, imposition of taxes that appear to offer some benefits, such as a VAT that permits

\footnotetext{
${ }^{14}$ LeJeune (2011) observes that EU countries have adopted relatively low thresholds, ranging from $€ 0$ to $€ 80,000$. Thresholds tend to be higher in countries that have recently adopted the VAT, such as Singapore that has a $€ 540,000$ threshold. Current practice suggests that countries may want to adopt a larger threshold but with a goal of bringing small firms into the VAT as administrative practices develop.
} 
credits for VAT implicit in inputs and capital purchases, appears to be more consistent with encouraging compliance than an additive income-based or presumptive tax. Taxing the small has considerable merit in terms of promoting tax fairness and helping integrate firms into the formal sector of the economy. A simplified version of a VAT, along with effective protocols to guide tax administrators and their relationship with taxpayers, can help small firms transition to compliance with the regular VAT regime. By easing taxpayers into the regular VAT system, one avoids the need to administer two parallel but disparate systems of taxation. Fledgling taxpayers may also perceive this phased-in integration as a source of horizontal reciprocity by means of treating them like other taxpayers: they are part of the same system that other businesses operate in and there should be no stigma associated with being "small" and subject to a separate and potentially pejorative presumptive system of taxation.

The design, implementation and administration of tax should be framed by the lessons emerging from the new field of behavioral economics. Generally there must be a recognition that psychological and social influences can vary substantially both across and within countries. Thus there is no single solution that could be applied generally across developing countries. Tax rates and revenue collection by small businesses will always give rise to incentives for noncompliance. Similarly, traditional sticks like costly audits and penalties can be effective in combating noncompliance. But a broader view is needed that recognizes that the fiscal exchange between taxpayers and state defines the nature of the effective social contract and thus the path of nation building. This social contract could conceivably be harmed by an inefficient, arbitrary and corrupt administrative apparatus, with implications for small traders but also society at large. It is also possible that the treatment of small traders, especially those transitioning from informality to formality, can yield direct benefits to the social contract as well as spillovers to others. In the end it is the will to tax and the will to do so in a fair and equitable fashion that may offer the long-term promise of better revenue mobilization in developing countries and a more effective state. Marginal analysis suggests that initial small business tax reforms should focus on firms (or types 
of firms) that would benefit most from being part of the formal sector because they need financing or access to broader markets (Everest-Phillips, 2008). The tax structure and administration could begin by identifying these firms (perhaps by industry) and placing the greatest focus on bringing them into an efficient tax system that does not impose overly burdensome compliance or tax costs. A lower priority could be placed on working with other industries.

Unintended consequences should receive careful consideration in small business tax policy. Agents will respond to the motivations created for them, and the structure of the tax system and administrative practices each create incentives. For example, the policy and practice of taxing large and small businesses should not and cannot be separated. Thresholds, lower rates, exemptions and other policies that limit or prevent taxation of small firms can change behavior of large firms (for example, organizing as a series of small firms), or prevent firms from wanting to become large. Either can entail a loss in economic activity or tax revenues. Thus, any deviation in the tax structure between small and large firms should be limited to areas that are least likely to be distorting. The Word Bank (2007) argues for presumptive taxes that are expected to bring in modest revenues but that get firms connected to the formal sector or preferred depreciation schedules with loss carryforwards that limit tax burdens for some small businesses in their introductory years. However, presumptive taxes work against other types of motivations created for small taxpayers. The World Bank argues against tax holidays that are more likely to be abused and we concur.

Similarly, aggressive third-party information sharing to enhance tax administration may harm formalization of the economy. For example, the use of information from the banking system to identify and collect tax from small firms may discourage use of the banking system as countries are seeking to expand formal financial sector activity. 
Changes in culture and resource allocation will ultimately be needed to achieve the broader social objectives of taxation in developing countries. This will not be easy to do in practice in part because of the long-term view and payoff period for policy changes. In the meantime, tax compliance will likely remain a game of cat and mouse between the tax administration and taxpayers. But there will be opportunities to change the course of tax administration and these opportunities need to be pursued and evaluated for their effectiveness. We know that taxes and penalties create incentives that taxpayers respond to. At the same time we know very little about how a kinder, more behavioral approach to tax administration can affect revenues and the broader goals of tax policy. 


\section{References}

Allingham, Michael G. and Agnar Sandmo. "Income Tax Evasion: A Theoretical Analysis." Journal of Public Economics 1 (1972): 323-38.

Alm, James. "Testing Behavioral Public Finance in the Laboratory." National Tax Journal 63 (2010): 63558.

Alm, James, Jorge Martinez-Vazquez and Benno Torgler, eds. Developing Alternative Frameworks for Explaining Tax Compliance. London: Routledge, 2010.

Alm, James, G.H. McClelland and William D. Schulze. "Why Do People Pay Taxes?" Journal of Public Economics 48 (1992): 21-48.

Bahl, Roy W. and Larry Schroeder. "The Real Property Tax." In Roy Bahl and Barbara D. Miller eds. Local Government Finance in the Third World: A Case Study of the Philippines. New York: Praeger, 1983, 46-81.

Bird, Richard, Jorge Martinez-Vazquez and Benno Torgler. "Tax Effort: The Impact of Corruption, Voice and Accountability." Center for Research in Economics, Management and the Arts, working paper 200713. Available at http://www.crema-research.ch/papers/2007-13.pdf.

Camerer, Colin. F. and George Lowenstein. "Behavioral Economics: Past, Present, Future." In Colin F. Camerer, George Lowenstein and Matthew Rabin (eds.), Advances in Behavioral Economics, 3-51. Princeton, NJ: Princeton University Press, 2004.

Chetty, Raj, Adam Looney and Kory Kroft. "Salience and Taxation: Theory and Evidence." American Economic Review 99 (2009): 145-77.

Coolidge, Jacqueline and Domagoj Ilic. "Tax Compliance Perceptions and Formalization of Small Businesses in South Africa." World Bank Policy Research Working Paper, 2009.

Cummings, Ron, Jorge Martinez, Michael McKee and Benno Torgler. "Tax Morale Affects Tax Compliance: Evidence from Surveys and an Artefactual Field Experiment." Journal of Economic Behavior and Organization (2009).

Ernst and Young. 2012. Total State and Local Business Taxes: State-by State Estimates for Fiscal Year 2011. July.

Everest-Phillips, Max, 2008. "Business Tax as State-Building in Developing Countries: Applying Governance Principles in Private Sector Development," International Journal of Regulation and Governance, vol. 8(2), 123-154.

Falkinger, Josef and Herbert Walther. "Reward Versus Penalties: On a New Policy Against Tax Evasion." Public Finance Quarterly 19 (1991): 67-79.

Foreign Investment Advisory Service. "Sector Study of the Effective Tax Burden: South Africa." April 2006. Available at https://www.wbginvestmentclimate.org/uploads/SouthAfricaTaxBurdenStudy.pdf. 
Frey, Bruno. "A Constitution for Knaves Crowds Out Civic Virtues." Economic Journal 107 (1997): 104353.

Ireland, N.J. "Optimal Income Tax in the Presence of Status Effects." Journal of Public Economics 81 (2001): 193-212.

Jolls, Christine, Cass R. Sunstein and Richard Thaler. "A Behavioral Approach to Law and Economics." Stanford Law Review 50 (1998): 1471-1550.

Kamleitner, Bernadette, Christian Korunka and Erich Kirchler. "Tax Compliance of Small Business Owners: A Review." International Journal of Entrepreneurial Behavior and Research (2012): .

Kahneman, Daniel and Amos Tversky. "Prospect Theory: An Analysis of Decision Under Risk." Econometrica 47 (1979): 263-91.

Kirchler, Erich, Stephan Muehlbacher, Barbara Kaslunger and Ingrid Wahl. "Why Pay Taxes: A Review of Tax Compliance Decisions." In James Alm, Jorge Martinez-Vazquez and Benno Torgler, eds., Developing Alternative Frameworks for Explaining Tax Compliance, London, Routledge, 2010, 15-32.

Krishna, Aradhna and Joel Slemrod. "Behavioral Public Finance: Tax Design as Price Presentation." International Tax and Public Finance 10 (2003): 189-203.

LeJenue, Ine. 2011. "The EU VAT Experience: What are the Lessons?" The VAT reader: What a Federal Consumption Tax Would Mean for America, Tax Analysts, pp. 257-282.

McCaffrey, Edward J. and Joel Slemrod, eds. Behavioral Public Finance. Russell Sage Foundation, New York: 2006.

Palmade, Vincent. 2005. "Industry Level Analysis: The Way to Identify the Binding Constraints to Economic Growth," World Bank Policy Research Working Paper No. 3551.

Richardson, Grant. "Determinants of Tax Evasion: A Cross-Country Investigation." Journal of International Accounting, Auditing and Taxation 15 (2006): 150-169.

Sarker, Tapan K. "Improving Tax Compliance in Developing Countries Via Self-Assessment Systems What Could Bangladesh Learn from Japan?" Asian Pacific Tax Bulletin 9 (June 2003): 1-34.

Schneider, Friederich, Andreas Buehn and Claudio E. Montenegro. "New Estimates for the Shadow Economies All Over the World." International Economic Journal 24 (2010): 443-461.

Schnellenbach, Jan. "Vertical and Horizontal Reciprocity in a Theory of Taxpayer Compliance." In James Alm, Jorge Martinez-Vazquez and Benno Torgler, eds., Developing Alternative Frameworks for Explaining Tax Compliance, London, Routledge, 2010, 56-73.

Shoup, Carl S. "The Taxation of Urban Property in Less Developed Countries." In Roy W. Bahl, ed. The Taxation of Urban Property in Less Developed Countries. Madison, WI: The University of Wisconsin Press, 1976, 271-83. 
Stern, Richard E. and Paul Barbour. "Designing a Small Business Tax System that Enhances Growth" Lessons from Africa." Foreign Investment Advisory Service and World Bank Group, December, 2005.

Tanabe, Noboru. "Blue Return System in Japan." In Patrick L. Kelley and Oliver Oldman, eds. Readings in Income Tax Administration. Mineola, NY: The Foundation Press, 1973, 221-30.

Torgler, Benno. "Speaking to Theorists and Searching for Facts: Tax Morale and Tax Compliance Experiments." Journal of Economic Surveys 16 (2002): 657-83.

Ventry, Dennis J., Jr. “Cooperative Tax Regulation.” Connecticut Law Review 41 (2008): 431-491.

World Bank, 2007 (a). Designing a Tax System for Micro and Small Businesses,"

World Bank, 2007 (b). "Micro, Small and Medium Enterprises: A Collection of Published Data." Available at http://rru.worldbank.org/Documents/other/MSMEdatabase/msme database.htm. 